\title{
Salt diffusion and salt diffusivity in sardine muscle (Sardinella aurita)
}

\author{
A. Sahli ${ }^{1}$, S. Bellagha and S. Bornaz ${ }^{2}$ \\ ${ }^{1}$ Institut National Agronomique de Tunisie (sahli inat tn@yahoo.fr) \\ ${ }^{2}$ Ecole Supérieure des industries Alimentaires de Tunis (
}

\section{Introduction}

Sardine (Sardinella aurita) is one of the widely distributed fish in Tunisia and represents an important source of low-cost dietary protein. However, the major factor preventing a wider acceptance of the product is its strong salty taste due to long salting period to ensure its preservation.

The objectives of this study were (i) to develop a finite difference model to predict the salt diffusion during wet salting and (ii) to determine the salt diffusivity in sardine muscle.

\section{Materials and methods}

\subsection{Raw material}

Fresh sardines were washed, scaled, gutted, skinned and filleted. The dorsal muscle was cut into two pieces of $60 \times 15 \times 5 \mathrm{~mm}^{3}$.

\subsection{Salting}

Brine salting was conducted in plastic containers at ambient temperature $\left(20^{\circ} \mathrm{C}\right.$ approximately). Fish muscles were immersed in three sodium chloride solutions: $26.5 \%$ (saturation), $21 \%$ and $15 \%(\mathrm{w} / \mathrm{w})$. During the first salting period, brine concentration was adjusted by renewing the brine solutions.

\subsection{Moisture content and Salt content}

Samples of three fish muscle were taken at predetermined intervals for analysis of salt and water content. They were determined according to AOAC norms (AOAC, 2000 and 1996).

\section{Mathematical and numerical modeling}

\subsection{Governing equations and initial and boundary conditions}

The governing equation for salt diffusion in onedimensional slab is given by:

$$
\frac{\partial C}{\partial t}=\frac{\partial}{\partial x}\left(D \frac{\partial C}{\partial x}\right)
$$

Initial and Boundary conditions:

$$
\begin{aligned}
& C=C_{0} \text { for } 0\langle x<l \text { at } t=0 \\
& C=C_{1} \text { for } x=0 \text { and } x=l \text { at } t>0
\end{aligned}
$$

Salt uptake $\left(M_{t}\right)$ at time $t$ is calculated from:

$$
M_{t}=\int_{0}^{l} C(x, t) \mathrm{d} x
$$

The value of $D$ was determined from the salt uptake profiles by minimizing the mean sum of the squares of the deviations (MSE) between the observed salt uptake values $\left(M_{i}\right)$ and predicted values $\left(\hat{M}_{i}\right)$ :

$$
M S E=\frac{\sum_{i=1}^{n}\left(M_{i}-\hat{M}_{i}\right)^{2}}{n-2}
$$

where, $C(x, t)$ is the concentration of salt in fish muscle; $C_{0}$ and $C_{l}$ are initial and equilibrium concentration of salt in fish muscle, respectively; $t$ is salting time; $x$ is space coordinate, $D$, salt diffusivity.

\subsection{Finite difference method}

To approximate the solution of eq. 1 with the initial and boundary conditions (Eq. 2 and Eq. 3), an implicit one dimensional finite difference scheme, using second-order central differentiating in space and a first-order backward difference in time was used. The simulation model was written in Fortran 77 and run on a HP-Unix mainframe system.

\section{Results and discussion}

\subsection{Experimental results}

Changes in salt and moisture content of sardine muscle during salting are presented in Figures 1a and $1 \mathrm{~b}$. As expected, higher brine concentrations extracted more water from and penetrated more salt into fish muscle, supporting the results from other workers on the salting of whole sardine fish (Bellagha et $a l ., 2006$ ).
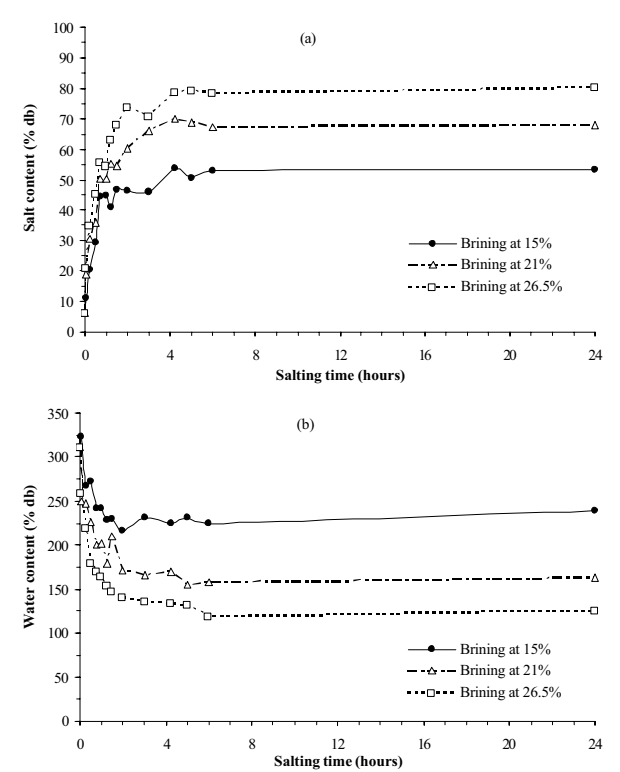

Figure 1. Effect of brine concentrations on mean (a) salt uptake and (b) water exudation 
Table 1 shows the results of chemical analysis of fish muscle before salting and at equilibrium for the three brine concentrations. Table 1 gives also the results of equilibrium distribution coefficient calculations $\left(K_{e}\right)$ performed on the data for all three runs. They had been realized using Del Valle and Nickerson (1967) expression:

$$
K_{e}=\frac{[\mathrm{NaCl}]_{\text {Fish }}}{[\mathrm{NaCl}]_{\text {Brine }}}
$$

Table 1. Experimental values of salt and water contents $(\% \mathrm{db})$ and equilibrium coefficient

\begin{tabular}{lcccc}
\hline \multirow{2}{*}{ Parameters } & \multirow{2}{*}{ Initial } & \multicolumn{3}{c}{ At equilibrium } \\
\cline { 3 - 5 } & & $15 \%$ & $21 \%$ & $26.5 \%$ \\
\hline Water content & 311.1 & 239.1 & 162.4 & 125.3 \\
Salt content & 6.2 & 53.4 & 68.1 & 80.2 \\
$\mathrm{~K}_{\mathrm{e}}$ & & 1.045 & 1.007 & 0.973 \\
\hline
\end{tabular}

\subsection{Model Validation}

To validate numerical model, the predicted concentration values were compared to the corresponding analytical solution for a constant diffusivity (Crank, 1975):

$$
\begin{gathered}
\frac{C_{1}-C(x, t)}{C_{1}-C_{\grave{a}}}=\frac{\pi}{4} \sum_{n=0}^{\infty} \frac{1}{(2 n+1)} \exp \left[-(2 n+1)^{2} \pi^{2} \frac{D \times t}{l^{2}}\right] \\
\times \sin \left[(2 n+1) \pi \frac{x}{l}\right]
\end{gathered}
$$

For this comparison, four terms values were used: initial and equilibrium concentration of salt in fish muscle, $C_{0}=0.012 \mathrm{~g} / \mathrm{g}$ and $C_{1}=0.533 \mathrm{~g} / \mathrm{g}$; filet thickness, $l=4.80 \mathrm{~mm}$ and fish muscle salt diffusivity $D=8.7810^{-11} \mathrm{~m}^{2} / \mathrm{s}$. Also, the comparison of the analytical solution with the numerical model predictions was based on the salt concentration at two extremes points of fish muscle: center node and sub-surface node. As can be seen from figure 2, results from numerical model agree with the analytical solution for the two nodes.

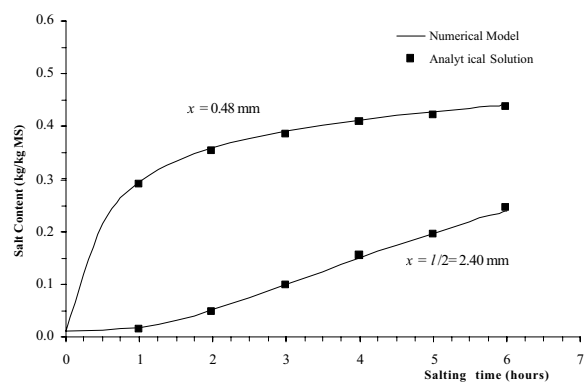

Figure 2. Example of comparison between numerical model and analytical solution in two nodes of fish muscle

\subsection{Identification of sardine muscle salt diffusivity}

The finite difference model verification involved comparison with experimental data. In the simulation, the finite difference framework was 100 layers of equal thickness $(\Delta x=0.005 \mathrm{~mm})$ and the time step was $\Delta t=0.005 \mathrm{~s}$. Figure 3 shows a comparison of observed and predicted mean salt uptake in sardine muscle for the three brine concentrations $(15,21$ and $21.5[\%(w / w)])$. The simulation results followed the trend of the experimental data for the three wet salting conditions. The mean differences between model predictions and measurements were 3.2, 2.4 and 2.9 [\%db], respectively. . The salt diffusivity, $D$, in sardine muscle were determined to be $8.8710^{-10} \mathrm{~m}^{2}$ $\mathrm{s}^{-1}$ for $15 \%(\mathrm{w} / \mathrm{w})$ brine and $7.8210^{-10} \mathrm{~m}^{2} \mathrm{~s}^{-1}$ for $21 \%$ and $26.5 \%(\mathrm{w} / \mathrm{w})$ brine conditions.

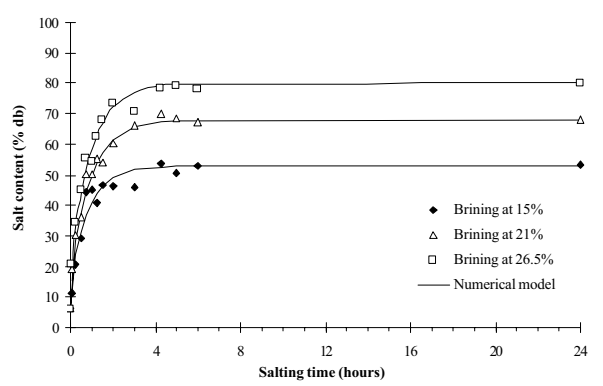

Figure 3. Comparison of observed and model predicted mean salt uptakes in sardine muscle

\section{Conclusion}

Salt diffusion in sardine muscle (Sardinella aurita) was investigated. Experimental study showed that brine concentration affect the rate of salt uptake and moisture loss in fish muscle; the lower the brine concentration the lower the rate. Also, a numerical model was developed to predict salt diffusivity. The model was first validated with analytical solutions and then verified by experimental data. The predicted salt diffusivity $D$, was found to be equal to $8.1710^{-10} \mathrm{~m}^{2} \mathrm{~s}^{-1}$.

\section{References}

AOAC. 1996. Official methods of analysis 952.08. Water content in seafood. Association of Official Analytical Chemists.

AOAC. 2000. Official methods of analysis 937.09. Salt (Chlorine as Sodium Chloride) in seafood. 17th edition. Association of Official Analytical Chemists. Bellagha S., Sahli A., Farhat A., Kechaou N., Glenza A. 2006. Studies on Salting and Drying of sardine (Sardinella aurita): experimental kinetics and modeling. Journal of Food Engineering, $\mathrm{xx}(\mathrm{x})$, xxxx-Xxxx

Del Valle F.R., Nickerson J. T. R. 1967. Studies on salting and drying fish. II. Dynamic aspect of the salting of fish. Journal of Food Science, 34, 218224. 